\title{
PATRIMONIO FISCAL DA UNIÃO E ESTADOS
}

\author{
«Il progressivo aumento del demanio \\ publico, la costante diminuzione del fiscale \\ se ha tutti i caratteri di una legge storica, \\ non deve però accogliersi in senso assoluto. \\ Il demanio fiscale neglio Stati moderne ha \\ due compiti, uno finanziario, di concorrere \\ a soperire alle spese publiche insieme alle \\ contribuzione; l'altro economico-sociale di \\ conservare dei beni e delle industrie che \\ sono condizioni generali di esistenza della \\ colletività $e$ che l'interesse personale sarebbe \\ tratto a distruggere o ad abbandonare.» \\ F. Flora, Scienza Delle Finanza,
} pag. 87 .

I Patrimonio Fiscal da União. Não havendo sido, até hoje, organisado o tombo ou o registro dos bens do dominio privado, nem existindo inventario ou uma lista sequer onde possam ser encontrados esclarecimentos de todo o patrimonio fiscal da União, difficil, senão impossivel, será determinal-o, especificadamente, e saber-se do seu valor exacto.

O conhecimento completo do patrimonio fiscal da União (I) requer differentes providencias administrativas e legislativas, um trabalho de investigação verdadeiramente afanoso e como, nestes ultimos tempos, vemos prestar-se attenção á essa ordem de cousas, não longe está o dia de obter-se a estatistica elucidativa de tamanha riqueza, em grande parte desaproveitada.

(I) Na exposição de motivos que acompanhou o projecto que, a 3 de Novembro de I90o, apresentamos á Camara Municipal de S. Paulo, este assumpto foi explanado sobre $o$ aspecto local. 
$\mathrm{Na}$ mensagem endereçada em 3 de Maio de 1903 ao Congresso Federal pelo actual presidente cons. Rodrigues Alves, mostrou s. excia. a necessidade de uma lei que defina o regimen a que devem ficar submettidas as terras incorporadas ao dominio nacional, por actos internacionaes, e só essa face da interessante questão é sufficiente para patentear a sua importancia e magnitude. (I)

O que existe publicado com alguma regularidade a respeito do assumpto, são trabalhos parciaes, incom. pletos, quasi que, exclusivamente, referentes aos proprios nacionaes.

Máu grado ao que fica exposto, vamos apenas dar uma ligeira noticia sobre o patrimonio fiscal da União, observando a ordem expositiva adoptada no $\S \mathrm{r} 2$, do nosso "Manual», onde se distingue bens do dominio territorial, industrial, commercial ou financeiro propriamente dito, (2) affirmando, ainda, ser immenso o seu valor, certamente excedente, em muito, de cem milhões de libras, $£$ 100.000.000, calculo aliás approximado e que, de momento fariamos, no presente, se a isso fosse mister. (3)

(I) Consulte-se o art. 34, $\S \S 29$ e 31 da Const. Federal, o parecer do dr. Serzedello Corrêa, em Julho de 1900 , sobre a receita geral da Rupublica, pag. 123 e o parecer do dr. T. A. Araripe Junior, sobre o veto presidencial de $2 \mathrm{I}$ de Julho de I896, opposto á resolução do Congresso $\mathrm{Fe}$ deral, regulamentando o art. 64 da Ccnst. da Republica e publicado no Diarro OfFicial, de 28 de Junho de 1903.

(2) A divisão do dominio privado do Estado em fixo e casual, adoptada pelo dr. Rodrigo Octavio, em sua monographia sobre «O Dominio da União e dos Estados», é feita sob o ponto de vista juridico.

(3) Diversos são os methodos propostos para a avaliação. E' proveitosa a consulta ao atlas estatistico e financeiro apresentado em I88I ao Congresso Internacional de Geographia de Veneza por Foville, o livro deste autor intitulado La France Économique, e a monographia de Turquan, na Revue D'Éc. Polit. de 1900 , pag. 167 , e o Tratado Elementar de EstatisTICA de Piernas Hurtado.-Apenas damos aqui os traços geraes. 
-Tratando-se do dominio tervitorial, o primeiro elemento de ponderação são as terras devolutas que, ex-vi, do art. 64, da Const. Fed. pertencem quasi que na sua totalidade aos Estados (r), excepção feita de uma zona de 14.400 kilometros quadrados no planalto central da Republica, para nella estabelecer-se a futura capital do Brazil, en cumprimento do disposto no art. $3 .^{\circ}$ da mesma Const.

Tendo-se em vista a disposição expressa na lei n. 60I, de i 8 de Setembro de 1850 e do decr. n. I.3 I 8, de 30 de Janeiro de 1854 que reservaram uma zona de dez leguas situada nos limites com paizes extrangeiros; e bem assim os proprios nacionaes espalhados pelos Estados (2) e a que se referem todos os relatorios da fazenda federal; bem como os terrenos da marinha e accrescidos numa costa de I.200 leguas de extensão, (3) ilhas, mares territoriaes, terrenos au-

(I) $\mathrm{O}$ art. 64, da Const. Fed. é assim expresso:-Pertencem aos Estados as minas e terras devolutas situadas nos seus respectivos territorios, cabendo á União sómente a porção de territorio que fôr indispensavel para a defesa das fronteiras, fortificações, construcções militares e estradas de ferro federaes. § unico.-Os proprios nacionaes que não torem necessarios para serviços da União, passarão ao dominio dos Estados, em cujo territorio estiverem situados.

(2) A proposito das terras devolutas o dr. Theodosio Silveira da Motta, em seu relatorio sobre proprios nacionaes, salientou a impossibilidade de ser precisamente determinada a parte das alludidas terras que devem ficar pertencendo á União por aquelle artigo da CONST. FED., isto é, a porção de territorio que fôr indispensavel para a defesa das fronteiras, fortificações, construcções militares e estradas de ferro federaes, e propõe, como medida que conciliaria os interesses da União e Estados:- Reservar, por lei ordinaria, á União as terras devolutas, cuja necessidade para serviços federaes, esteja verificada, ficando os Estados, onde estiverem ellas situadas com o direito de dispor das restantes como entenderem; comtanto, porém, que todas as terras devolutas fiquem sujeitas ao onus de ser entregues ao governo federal, quando por elle exigidas para o serviço da União, não tendo as pessoas, que forem privadas das mesmas terras, direito á qualquer indemnisação, senão pelas bemfeitorias que nellas possuirem. Relatorio Da FAzenda Federal, de 1902, pag. 256.

(3) O Relatorio da Fazenda Federal de 1899, pag. 45, allude ao quasi completo abandono dos terrenos da marinha, indicando os que por elles devem ser tomados. Os foros pela occupação desses terrenos que apenas figuram no orçamento dả receita na insignificante importancia de 30:000\$000 e os laudemios na de 80:000\$000, começaram a fazer parte da renda da União pela 
riferos e jazidas diversas, algumas dellas abandonadas, (I) não se póde deixar de convir que o seu valor, a despeito da restricção do texto constitucional, é ainda de grande monta (2).

-O dominio industrial, com ou sem monopolio, tem tido um desenvolvimento consideravel, devido ao facto de serem ultimamente incorporadas ao patrimonio da União estradas de ferro na extensão de 2.148 .83 kilometros, num valor de $£$ I 4.605 .380 (3).

lei n. 25, de 30 de Dezembro de $1891 .-0$ decr. 4105, de 22 de Fevereiro de 1868 , que é talvez a unica disposição que regula o assumpto, ainda está para ser adaptado ás condições do actual regimen politico. O RELAToRjo DA FAzenda Federal de 1900, pag. 49, allude á essa lacuna da actual legislação fiscal.

(I) O recente caso das areias monasiticas é um exemplo digno de ser meditado. Como se vê pelo Relatorio Da FAzenda Federal de I 899, pag. 42 especuladores, a titulo de lastro para navios, tiravam das costas da Bahia e Espirito Santo toneladas e toneladas desse mineral que é a monasite de onde se extrahe o thorium, elemento primordial para as modernas applicações industriaes. . e por largo tempo, assim se locupletaram illicitamente com aquelle rico veeiro nacional.

(2) Dr. Amaro Cavalcanti, Elementos DE FinAnÇAs, pags. I03 á I67.

(3) No Correio Paulistano, de 24 de Outubro de 1892, publicamos um artigo sobre a encampação das estradas de ferro garantidas pela União, e que foi transcripto pelo Jornal do Commercio, de 28 do mesmo mez. Nesse trabalho dissemos:-

Resumindo, pois, o resgate obedeceu ás seguintes linhas geraes: a) pagamento de apolices de $4 \%$ de juro e $1 / 2 \%$ de amortização para occorrer a uma renda correspondente a $\mathrm{um}$ rendimento liquido das estradas, calculado na base do termo médio dos cinco annos mais prosperos dos ultimos sete; b) constituição em Londres, de uma caixa de resgate ou amortização das apolices entregues em pagamento, para a qual serão destinadas as differenças entre as sommas devidas pelas actuaes garantias e as dos juros e amortização das novas apolices, bem como as provenientes de arrendamento ou alienação das estradas. Vide 0 n. VIII, art. 22, da lei n. 653, de 23 de Novembro de 1899

Do quadro geral annexo ao Relatorio do encarregado dessa operação, dr. José Carlos Rodrigues, se vê que os 2.I48,83 kilometros das estradas custaram $\& \mathrm{I} 4,605.380$, em apolices de $4 \%$. Tomando o preço médio destas apolices a $66 \%$ esta somma representa $£ 9.736,920$ em dinheiro, ou $£ 4.53 \mathrm{I}$ ou 40:27 I \$000, ouro por kilometro, de todas as estradas, inclusive de bitola larga e outras de construcção difficil, como a do Paraná, Minas e Rio custaram mais do dobro disso. As garantias devidas por periodos de 9 a 44 annos sobre o capital das estradas resgatadas, sommam nos primeiros annos $£ 83$ I.750. E como os $4 \%$ de juros das emissões feitas de $£$ I $4,605.380$ sommam $£ 584.2$ I 5 , terá o Thesouro nesse periodo das garantias, a economia annual de $£ 247.535$ que irão para a "Caixa de Resgate» em Londres ou fundo de amortização. A' esta somma accrescenta-se o producto do arrendamento das estradas ou $\&$ I 31.065 ; 
A rêde de viação ferrea nacional, fracções desprezadas, attingia até $3 \mathrm{I}$ de Dezembro de 1902 a 16.000 kilometros. Destes, mais da terça parte ou $5.44 \mathrm{I} \mathrm{k}$. é de propriedade da União, assignalando-se a «Estrada de Ferro Central» que, até aquella data, tinha I.300 kilometros em trafego, representando para o Estado uma immobilisação de cerca de 200.000:000\$000 e um rendimento bruto de 30.000:000\$000. Sobre essa rica propriedade não pesa onus algum, e não só pelo seu grande valor intrinseco como pelo seu alcance social e politico, é ella considerada como um instrumentum regni.

De par com esses bens nacionaes estão outras industrias com monopolio taes como a casa da moeda, a fabricação da polvora, o correio geral da Republica, a impressão das leis, decretos e mais actos dos poderes federaes, concessão de penas d'agua na Capital Federal e sem monopolio, a imprensa nacional e o Diario Official, o telegrapho federal, a fabrica de ferro do Ipanema, os estabelecimentos federaes de instrucção, estradas de ferro, arsenaes da marinha e guerra, casa da correcção, assistencia de alienados e outros cujo

sommando-se estas duas contribuições o total de $£ 378.600$ applicavel á compra de apolices no mercado. Ao typo de 80 , esta quantia bastará para comprar $31 \%$ do total emittido. Logo, suppondo-se que o cambio não melhore de $12 \mathrm{~d}$. ou que a renda bruta das estradas não augmente absolutamente no seguinte decennio, a actual amortização basta para, em menos de 12 annos, haver recolbido a metade de toda a emissão. $\mathrm{Na}$ hypothese natural do augmento progressivo da renda alludida, a emissão poderá ser resgatada integralmente em I7 annos, convindo não esquecer que o governo tem tambem a seu favor o juro accumulado das apolices que vai resgatando. Finalmente, a somma de $£ 9,736.820$, em dinheiro, representada nas estradas que o governo comprou, é um tanto menor do que a somma em dinheiro que o governo devia ás respectivas empresas por conta da garantia de juros, taes garantias sendo descontadas a $4 \%$ segundo os periodos em que deveriam decorrer.

Pode-se, pois, affirmar que o governo comprou as estradas por alguma cousa menos do que o valor, commutado devidamente de suas proprias garantias, pagando esse valor em apolices de $4 \%$, a $66 \%$, typo mais elevado da que o dos mercados europeus, quando se fizeram as transaç̧ões. 
movimento financeiro consta dos relatorios da fazenda federal. (I)

- Com relação ao dominıo privado commercial $e$ financeiro da União é igualmente sensivel a falta de dados estatisticos, sendo fóra de duvida que attingem a um valor consideravel, pois, em muito devem importar a divida activa federal externa e interna (2) conjunctamente com os saldos á disposição no paiz e no extrangeiro, as restituições, os titulos de associações anonymas, os juros recebidos annualmente a fundos de resgate e de garantia a que se referem as differentes especialisações da lei do orçamento da receita.

--Cumpre finalmente notar que os bens patrimoniaes da União e dos Estados gozam de completa isenção tributaria (3) nos termos do art. ı o, da Const. Fed.

(I) Ainda sobre as estradas de ferro força é reconhecer que todas as nações modernas procuram encampal-as, não só para attender as conveniencias economicas, politicas e sociaes, como obter elementos de formação de receita. A Allemanba resgatou grande numero de suas vias ferreas, possuindo hoje.. 41.000 kil. ou a maior extensão conhecida; a Russia já possue 40.000 kil.; a França 33.00o, seguindo nesta ordem as demais nações como a Austria, Belgica, Allemanha, Dinamarca, Suecia, Noruega e outros paizes. Vide:-Schonberg, Manual DE Ec. Polit., trad. it. de Bocard, pag. 269; Wagner, Scienza DELle Finanza, trad. de Ferrari, vol. I, pag. I59; Leroy Beaulieu, Traité DE LA ScIEnce Des Finances, vol. I, pag. 104 ; Didimo da Veiga, Revista da Faculdade Livre de Direito do Rio, vol. I, pag. 20; Viveiros de Castro, Tratado dos Impostos, pag. 436.

(2) A divida activa e externa, pela tabella n. Iannexa ao RELATORIO DA FAzenda FEDERAL, apresentado em I903, pelo Dr. Leopoldo de Bulhões, attingia a $3 \mathbf{r}$ de Dezembro de J902, á 24.3 I2:162\$406, sendo responsavel pela quasi totālidade, a Republica do Uruguay. Não estão incluidas nesse quantum as despesas feitas com a divisão auxiliar que esteve em Montevideo, em I854 e I855, e que devem ser pagas ex-vi do tratado de 12 de Outubro de 185 I e accordo de 5 de Agosto de 1854 .

--A divida activa interna attingia á 18.05 I:3 I8\$614, proveniente dos emprestimos feitos aos Estados da Bahia e Pernambuco. Infelizmente de muitas outras parcellas da divida interna, como os emprestimos bancarios com ou sem juros... apenas se tem vaga noticia.

(3) $\mathrm{O}$ art. Io, da Const. Fed, é assim expresso: «E' prohibido aos Estados tributar bens e rendas federaes ou serviços a cargo da União e reciprocamente. 
II Patrimonio fiscal dos Estados do Brazil. Não menos custoso, $\S$ t. $^{\circ}$, é ainda formar-se uma ideia approximada do dominio privado de cada um dos Estados do Brazil, attenta á falta quasi absoluta de dados estatisticos!

Esse patrimonio fiscal, na maior parte representado por terras devolutas, inteiramente habitaveis, que, em extensão ou superficie, excedem ao territorio de algumas nações da Europa reunidas-é evidentemente incalculavel. Um exemplo póde fornecer ligeira ideia do que fica dito. Pertence ao Estado do Pará, entre una myriada de ilhas, junto á fóz do do Amazonas, a ilha de Maraj6 que tem 42.100 kilometros quadrados. Pois bem, essa ilha é maior do que cada um dos paizes • da Europa, Belgica, Suissa, Hollanda, Dinamarca (I) e mesmo de alguns Estados brazileiros como Espirito Santo, Alagoas, Sergipe e o districto federal!

Nos termos do art. 64, da Const. Fed., ficaram pertencendo aos Estados as terras devolutas situadas nos seus territorios; e os mais aquinhoados pelo dispositivo constitucional foram os onze seguintes:-Amazonas, Matto Grosso, Pará, Goyaz, Minas, Bahia, Maranhão, S. Paulo, Piauhy, Paraná, Santa Catharina, ficando os demais com uma superficie bem limitada. (2)

(I) Vide o Jornal do Commercio, de 21 de Norembro de I895.

(2) A superficie dos Estados é a seguinte:-Amazonas I.900.000 kilometros; Matto Grosso I.607.000; Pará I.140.000; Goyaz 644000; Minas Geraes 633.000; Bahia 576.000; Maranhão 303.000; Rio Grande do Sul 288.000: São Paulo 264.000; Piauhy 208.000; Paraná 185.000; Ceará. 158.000; Santa Catharina 99.000; Pernambuco 94.000: Parahyba 57.000; Rio Grande do Norte 46.000; Rio de Janeiro 44.000; Espirito Santo 42.000; Alagôas 29.000; Sergipe 23.000; Districto Federal 1.900.

- O Dr. Affonso Celso, em seu livro Porque me ufano do meu paiz. sobre a grandeza territoríal do Brazil escreve o seguinte:-O Brazil é um dos mais vastos paizes do globo, o mais vasto da raça latina, o mais vasto do novo mundo, a excepção dos Estados Unidos. E' pouco menor que toda Europa. Rivalisa em tamanho com o conjuncto dos outros paizes da America Meridional. Representa uma decima quinta parte do orbe terraqueo. Só a Rus. 
Esses vastos dominios, naturalmente destinados á expansão colonial, constituem verdadeiras reservas cujo valor real um futuro não mui remoto, certamente revelará.

-Quanto ao patrimonio industrial e financeiro propriamente dito, nenhumas informações nos foi possivel obter, ainda mesmo dos Estados mais populosos. (I)

A despeito do que fica resumidamente exposto, procuramos organisar em relação ao Estado de S. Paulo uma estatistica que no seu conjuncto, e embora in. completa, dá perfeita ideia da relevancia do assumpto.

Essa estatistica approximada do patrimonio fiscal do Estado de S. Paulo, exclusão feita da parte referente aos 176 municipios, em 3 I de Dezembro de I 902, é pois a seguinte: (2)

sia, a China e os Estados Unidos o excedem em extensão. E' quatorze vezes maior que a França, cerca de trezentas vezes maior do que a Belgica.

A sua circumscripção territorial menos dilatada, Sergipe, sobreleva a Hollanda, a Dinamarca, a Suissa, o Haiti e Salvador. Cada um dos municipios em que se sub-divide o mais amplo, o Amazonas, equivale a Estados, còmo Portugal, Bulgaria e Grecia. Pará, Matto Grosso ultrapassam qualquer nação Europea, salvante a Russia. "O Brazil é um mundo». Estados?

Se assim é como não ser tambem grande o patrimonio territorial dos

(I) $O$ Estado de Minas deve ter um valioso patrimonio fiscal. Só em estradas de ferro (subvenções, emprestimos e acções) possue nada menos de cincoenta e sete mil contos. Dr. David Campista, Relatorio Da SecretaRIA DAS FINANÇAS de I902, pag. I 80.

(2) Não incluimos nesta estatistica certos bens como o material dos estabelecimentos publicos e da força policial por serem especialmente affectados ao serviço publico. Da mesma forma não incluimos no activo a importancia da receita publica (comquanto possa ella ser especialisada ou posta parcialmente em hasta publica) por corresponder exactamente a outro serviço a despeza publica. Apenas computamos bens de prompta mobilisação ou alienação, que possam servir de base á operações de credito, emfim o patrimonio disponivel para contrabalançar o passivo.

-Quanto aos municipios ainda é cedo para obter-se uma estatistica como a dos departamentos da França, onde se sabe muito bem... «ce que vaut chaque departement.»V Turquan, Revue D'Ec. Polit., de I (s)o, pag. I69. Em nosso livro Estudo ECONOMico e FinANCEIRo sobre o Estado DE SÃo PAUlo, cap. "Riqueza Publica», pag. 22, calculamos o patrimonio fiscal dos municipios em 1897, no valor de cincoenta mil contos. 


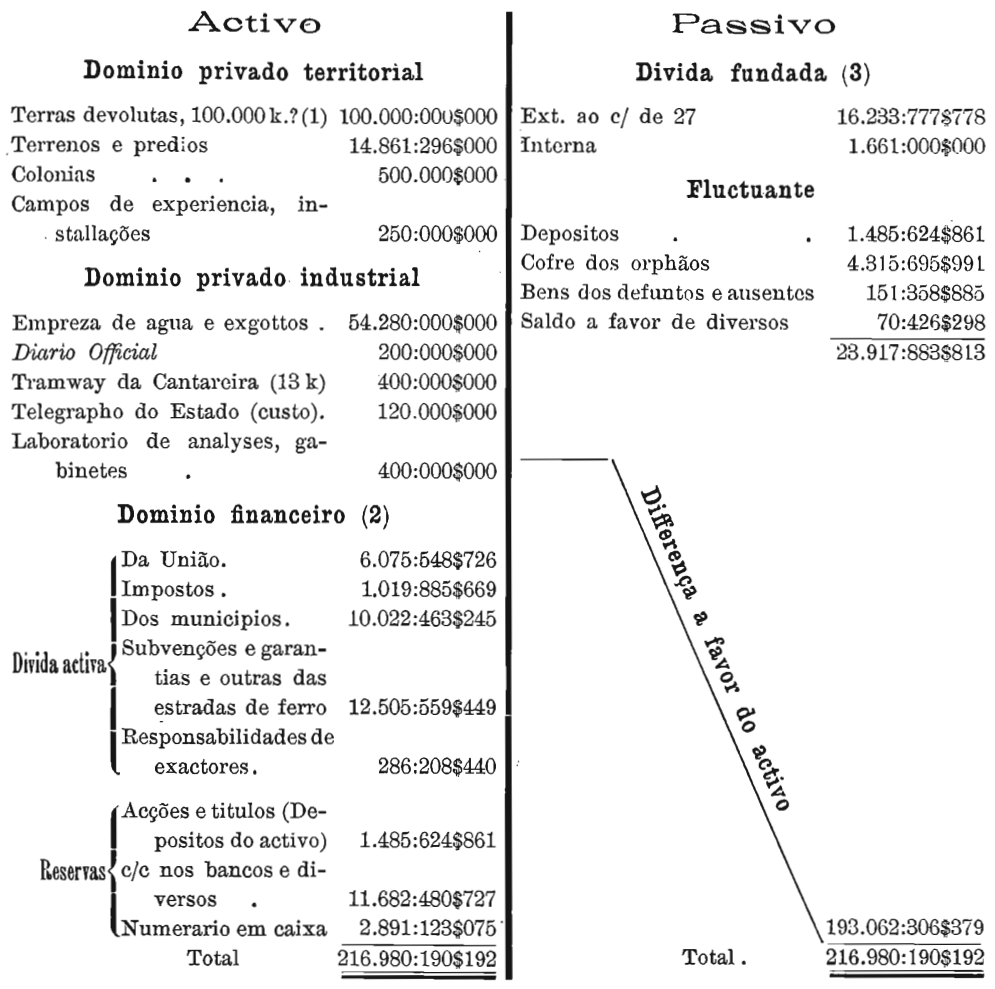

(I) Nos nucleos coloniaes tem-se vendido o hectare desde o preço de $16 \$$ até $80 \$ 000$. Pois bem sob a base de $10 \$ 000$ o hectare como estipula, para terras de cultura, o $\S 5$ do art. 5 da lei estadual n. 323 , de 22 de Junho de 1895, toda superficie pertencente ao Estado de S. Paulo e que em sua maioria são terrâs de excellente cultura representa seguramente um valor de cem mil contos. E' possivel que se attribua ás terras devolutas valor negativo e incerto; sem o computo dellas impossivel será conhecer o dominio privado global do Estado. Demais podem ser objecto de prompta mobilisação e de incalculavel resultado. Para isso bastaria ser implantado entre nós o regimen do Homestead que engrandeceu a Republica Norte Americana, cobrindo de habitações um immenso territorio.

«La tierra pública es una riqueza»? inquire o Dr. José Terry, em seu livro sobre FINANZAS, pag. 296.- «Propiamente no lo es, mientras no sea ritil y apropriada. Y no será útil y apropiada mientras no se le incorpore el trabajo y el capital. Sin capital y sin trabajo la tierra es un bien que no se utitisa, que no sirve ni para la producción ni para la industria.» Esta noção soffre restriç̧ões si considerarmos a questão em absoluto..

(2) Dr. Firmiano Pinto, Relatorio Da Fazenda Estadual, de 1903, pag. 88 .

(3) Relatorio da Fazenda Estadual de 1903, cit, pag. ior. 
No senado do Estado de S. Paulo, em sessão de 27 de Abril de I798, o dr. Ezequiel Ramos, salientando a conveniencia de publicar-se annualmente um quadro estatistico acerca do patrimonio fiscal, apresentou um projecto (I) que pende de deliberação do Congresso e cuja approvação será de indiscutivel utilidade. Esse elemento informativo, uma vez obtido, contribuirá para haver sempre pleno conhecimento e a maior prudencia, por parte do legislador, por occasião de serem autorisadas operações de credito ou contrahidos quaesquer compromissos que, não raro começam suavemente, sem serem por assim dizer apercebidos, pouco e pouco se avolumam, afinal de contas ficam eternamente onerando aos contribuintes ou ao povo, sugando as forças vitaes da nação!

S. Paulo, I 9-1 2-903.

Dr. Weiga Filho

(I) Eis a integra do projecto. O Congresso Legislativo do Estado de S. Paulo decreta: Art. $\mathbf{I}^{\circ}$ O director do Thesouro do Estado terá além das attribuições definidas pelo decr. 336 , de 15 de Fevereiro de 1896 , mais a seguinte: I Mandar fazer, annualmente, pelo pesscal da sub-directoria da contabilidade, em ordem chronologica de dia, mez e anno o quadro de arrecadação das rendas e valores pertencentes ao Estado, com individuação de sua procedencia e o das despezas feitas, declarando-se a lei e o funccionario que as autorisou; II Prescrever a organisaşão de uma exposisão do activo e passivo do Estado, comprehendendo, discriminadamente, em verbas particularisadas a divida interna e externa, fundada ou fluctuante, os saldos existentes no thesouro de maneira a tornar facilmente conhecida a situaşão real da economia do erario publico; III Determinar o arrolamento dos proprios estaduaes, com descripção do seu estado e utilisação. Art. 2. Esses trabalhos depois de revistos e assignados pelo director do Thesouro, que responderá por sua exactidão, sob pena de responsabilidade, devem ser presentes ao Congresso no dia de sua installação. Art. $3 .^{\circ}$ Revogam-se as disposições em contrario. 